JOURNAL OF SECURITY AND SUSTAINABILITY ISSUES

ISSN 2029-7017 print/ISSN 2029-7025 online

2019 March Volume 8 Number 3

https://doi.org/10.9770/jssi.2019.8.3(13)

\title{
TERRORIST ATTACKS ON SELECTED SOFT TARGETS
}

\author{
Petra Beňová1, Šárka Hošková - Mayerová ${ }^{2}$ Josef Navrátil ${ }^{3}$ \\ 1,2, University of Defence, Kounicova 65, 66210 Brno, The Czech Republic \\ ${ }^{3}$ Ambis Colledge, Lindnerova 575/1, 18000 Praha
}

E-mails: ${ }^{1} p e t r a . b e n o v a @ u n o b . c z ;{ }^{2}$ sarka.mayerova@unob.cz, ${ }^{3}$ josef.navratil@unob.cz

Received 10 December 2017; accepted 15 February 2019.; published 30 March 2019

\begin{abstract}
Soft targets are places that are typical of a large concentration of population and a low level of security. Compared to so-called hard targets, these places are not permanently protected. Soft targets are shopping centers, clubs, restaurants, schools, transport, airport terminals, gatherings, entertainment centres etc. Soft targets are increasingly being chosen as a target for terrorists. It is caused mainly by its characteristics. This paper focuses on the safety situation of soft targets due to current threats of terrorist attacks, it specifically addresses the issue of safety in the entertainment industry. Based on the available terrorist attacks database, terrorist attacks, attacks on soft targets and entertainment during the years $1970-2017$ were evaluated. There is an increase specifically in attacks on soft targets and attacks on entertainment in the years 2005 - 2015 and the most in 2011 - 2015. Based on the analysis of available data, basic safety measures have been designed to increase the resilience of soft targets - entertainment centres that are used for other objects and events with a large number of citizens. The aim of this article is to establish basic criteria to identify soft targets and to assign a level of importance to the criteria based on a questionnaire survey carried out among professionals.
\end{abstract}

Keywords: Entertainment industry, safety, soft targets, terrorism, terrorist attack

Reference to this paper should be made as follows: Beňová, P.; Hošková - Mayerová, Š.; Navrátil, J. 2019. Terrorist attacks on selected soft targets, 453-471. https://doi.org/10.9770/jssi.2019.8.3(13)

JEL Classifications: H55

\section{Introduction}

Nowadays, there is a growing number of attacks which are caused by individuals or groups. These individuals or groups are often labelled as terrorists. New and more attractive targets for terrorists are crowded places. Due to the increasing number of terrorist attacks or other violent attacks on places with a high concentration of people (so-called soft targets), it is necessary to secure these places and prevent them from being attacked. The issue of soft targets, their protection, security, and citizen's protection is therefore a very current. An example of this issue are the recent attacks in Spain (attack on Las Ramblas in Barcelona), Britain (attack on London Bridge, Manchester Arena, and Westminster Bridge), a series of attacks in Paris and many others.

The level of threats to soft targets has been increasing, especially due to their attractiveness, ease of access, availability and number of people. There is a need to identify areas that may be potentially at risk and to take preventive measures to improve their safety and security. Relating soft targets, the greatest attention must be paid to objects or events that involve a large number of people in a relatively small area, such as temples, schools, universities, hospitals, sport events, concerts etc.

Current laws and standards do not regulate the definition and characterization of soft targets. There are no clear criteria for determining soft targets, nor for procedures that would determine what can be included in these 
targets and what does not belong there anymore. There is a number of documents in the Czech Republic dealing with this issue and trying to clearly define soft targets (Ministry of the Interior, 2017).

The subject of our investigation are terrorist attacks directed at the entertainment industry, where venues such as clubs, concerts, festivals, etc. are very common targets for terrorists for their insufficient or minimal security measures.

In general, soft targets are characterized as places with high concentration of people and low level of security. According to the terminology dictionary of the Ministry of the Interior, Czech Republic, soft targets are defined as "public frequented sites, easily attackable objects or non-military sites that are not permanently guarded by armed forces or otherwise, or are not guarded at all. Such places and objects are characterized, in particular, by a permanent or temporary high concentration of persons, of a symbolic, cultural or religious significance, or constitute an important part of the state's infrastructure. The disruption of them has a negative impact on the functioning of the system and on society".

Recently, the European Commission defined soft targets as locations that "are vulnerable and difficult to protect and are also characterized by the high likelihood of mass casualties in the event of an attack" (European Commission, 2017). Typical soft targets include:

- shopping centers, market places, supermarkets;

- railway and bus stations, subway stations, airport terminals;

- sporting arenas and stadiums;

- cinemas, theatres, concert halls;

- schools, dormitories, libraries;

- religious sites;

- gatherings, parades, demonstrations;

- bars, restaurants, clubs, dance clubs, hotels;

- hospitals, medical centers;

- tourist monuments and places of interest, museums, galleries.

For more details, see (Kalvach, 2016; Ministry of the Interior, 2017).

The Global Terrorism Database divides the soft targets into 22 categories, which are further divided into 113 subcategories. The authors have chosen the subcategories the Entertainment/Cultural/Stadium/Casino area which was subjected to in-depth research. The reason for the research of the Entertainment soft target was especially a high concentration of people in these areas and a relatively high risk of committing an attack with a great number of victims.

\section{Methodology and data collection}

The issues studied concern security questions, and therefore some data and information are not available for the public. In some cases, the majority of data is classified. These data are then available only to the police and security forces. It is because of an easy misuse of data and especially information.

\subsection{Data collection from public resources}

The only source of information which is verified and regularly updated is the Global Terrorism Database (GTD), which was used as a resource for this article. This database is a comprehensive overview of the terrorist attacks committed between 1970 and 2018. Moreover, it is an open-source database including information on terrorist attacks around the world. The GTD includes systematic data on domestic as well as transnational and international terrorist incidents that have occurred during this time period and now includes more than 
180,000 cases. For each GTD incident, there is information available on the date and location of the events, weapons used and nature of the target, the number of casualties, and, when identifiable, the group or individuals responsible. Main characteristics of the GTD are:

- contains information on over 180,000 attacks;

- currently the most comprehensive unclassified database on terrorist events in the world;

- includes information on more than 88,000 bombings, 19,000 assassinations, and 11,000 kidnappings since 1970;

- includes information on at least 45 variables for each case, with more recent incidents including information on more than 120 variables;

- over 4,000,000 news articles and 25,000 news sources were reviewed to collect incident data from 1998 to 2016 alone (National Consortium for the Study of Terrorism and Responses to Terrorism (NCSTRT), 2017).

\subsection{Survey}

Another data source that served to meet the research goal was data from the questionnaire survey. These data served to determine the importance of criteria for recognizing the so called "soft target". The questionnaire survey was carried out on a sample of 95 respondents from the whole Czech Republic. These were experts from different areas of safety. They were contacted by Czech police officers, HZS staff, security agency staff, and security technicians at the offices of municipal councils. Out of the sent questionnaires, 88 returned. The selection of the addressed respondents was made so that all regions of the Czech Republic were covered. Last but not least, the emphasis was also on the even representation of large and small towns and municipalities.

\subsection{Research questions formulation}

The authors of the article drew from the above-mentioned database. They carried out a research of available data and used them to work out basic descriptive statistic. They focused especially on answering these questions:

- How is the number of terrorist attacks and number of victims progressing?

- How is the number of soft targets attacks progressing?

- How is the way the terrorist attacks are done progressing and is the target of these attacks statistically significantly changing?

Out of the total number of possible terrorist attacks targets, as differentiated by the database, the following soft targets have been chosen:

Table 1. Type of soft target

\begin{tabular}{|c|c|c|c|c|c|c|c|}
\hline Code & Type of soft target & Code & Type of soft target & Code & Type of soft target & Code & Type of soft target \\
\hline 2 & Restaurant & 57 & Civilian Maritime & 80 & Memorial & 100 & Train \\
\hline 8 & Hotel & 60 & Port & 81 & Museum & 101 & Bus station \\
\hline 11 & Entertainment & 74 & Market place & 86 & Place of worship & 102 & Subway \\
\hline 44 & Airport & 78 & Procession & 96 & Tour bus & 103 & Bridge \\
\hline 49 & School & 79 & Public areas & 99 & Bus & 104 & Highway \\
\hline
\end{tabular}

Source: data (National Consortium for the Study of Terrorism and Responses to Terrorism, 2017), elaboration: authors

In pursuance of gaining more knowledge and new information regarding the safety measures applied on soft targets, some methods of scientific work have been used:

- Method of controlled interviews with specialists from Police of the Czech Republic and Fire Rescue Service of the Czech Republic.

- Research of current state of the subject matter - survey of measures and processes actually used in practice. 
- Basic statistical methods, linear trends, trends equation.

- Establishing possible criteria to identify soft targets.

- Sorting and summing method.

\section{An analysis of the current state of terrorist attacks}

According to the records of all known attacks obtained from the Global Terrorism Database (National Consortium for the Study of Terrorism and Responses to Terrorism, 2017), there has been 181,691 atacks in 175 countries from 1970 to 2017. At the time of researching this issue, the year 2016 and 2017 had not been available in the database yet. Therefore, we focused only on events from 2015 and the year 2016 and 2017 was later used as a verification year for the calculated prediction of terrorist attacks for the upcoming years. The distribution of the number of terrorist attacks in this time period is shown in Figure 1, along with the trend equation expressed with the polynomial functions of 4th degree:

$$
y=0.0207 x^{4}-1.1683 x^{3}+9.721 x^{2}+293.74 x-564.04
$$

The reliability of this trend is quite high because the value $\mathrm{R}^{2}$ is 0.8298 (Vališ et al., 2014). Source of data for figures 1-7 and tables 1-3 is the database (NCSTRT, 2017), the elaboration was done by authors.

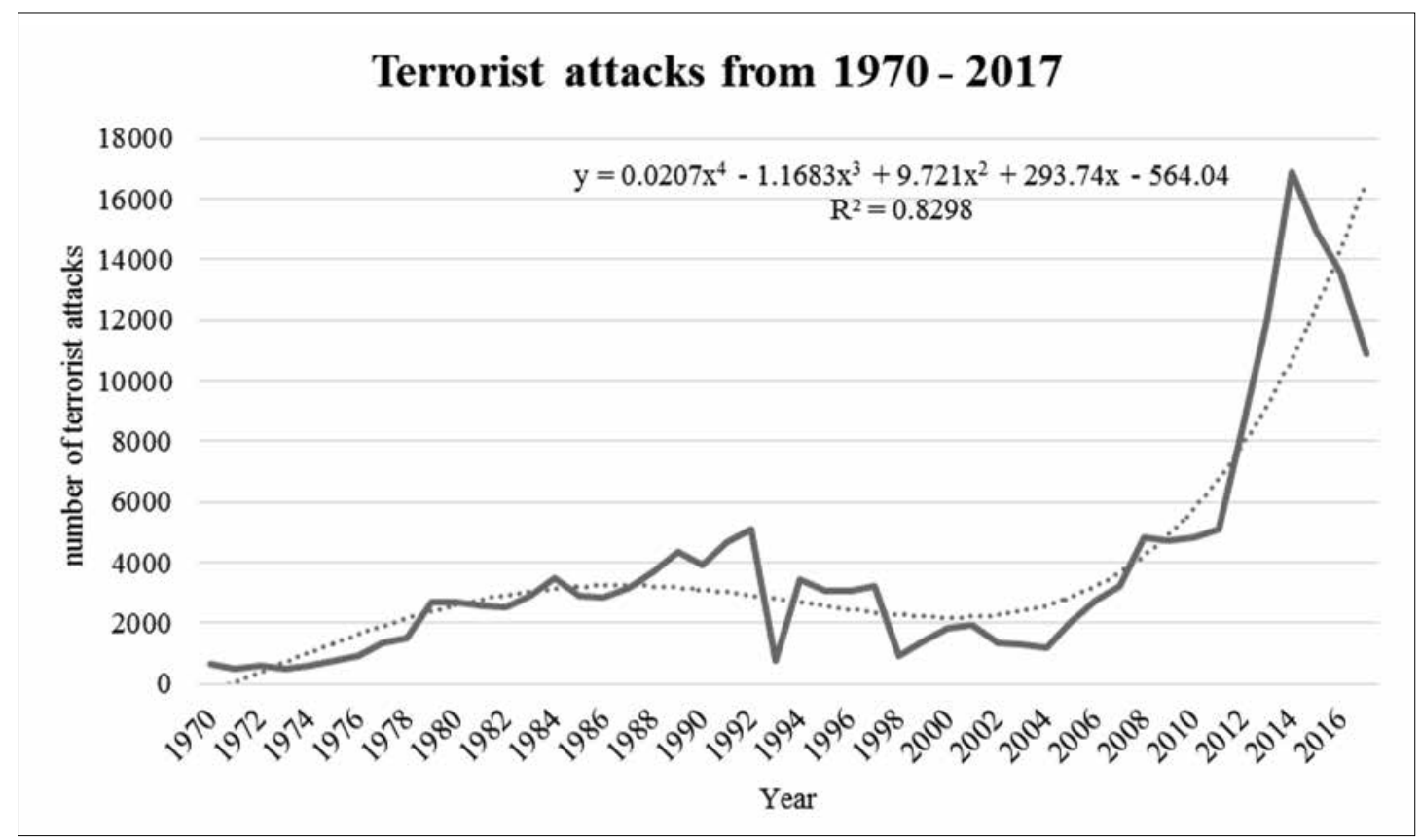

Fig. 1. Number of all terrorist attacks from $1970-2017$

Source: data (NCSTRT, 2017), elaboration: authors

The highest number of terrorist attacks occurred in 2014, with the total of 16.903 attacks. The number of terrorist attacks on soft targets between 1970 and 2017 was 21,924. Of these, 941 attacks were directed to entertainment industry.

The Table 2 shows the number of terrorist attacks, attacks on soft targets and entertainment industry in individual years. 
Table 2. Comparison of the number of terrorist attacks

\begin{tabular}{|c|c|c|c|c|c|c|c|}
\hline \multirow[b]{2}{*}{ Year } & \multicolumn{3}{|c|}{ Number of } & \multirow[b]{2}{*}{ Year } & \multicolumn{3}{|c|}{ Number of } \\
\hline & $\begin{array}{l}\text { terrorist } \\
\text { attacks }\end{array}$ & $\begin{array}{l}\text { attacks on soft } \\
\text { targets }\end{array}$ & $\begin{array}{c}\text { attacks on } \\
\text { entertainment } \\
\text { industry }\end{array}$ & & $\begin{array}{l}\text { terrorist } \\
\text { attacks }\end{array}$ & $\begin{array}{l}\text { attacks on soft } \\
\text { targets }\end{array}$ & $\begin{array}{c}\text { attacks on } \\
\text { entertainment } \\
\text { industry }\end{array}$ \\
\hline 1970 & 651 & 105 & 9 & 1994 & 3456 & 467 & 27 \\
\hline 1971 & 471 & 64 & 6 & 1995 & 3081 & 492 & 44 \\
\hline 1972 & 568 & 29 & 6 & 1996 & 3058 & 462 & 32 \\
\hline 1973 & 473 & 21 & 0 & 1997 & 3197 & 493 & 26 \\
\hline 1974 & 581 & 56 & 10 & 1998 & 934 & 154 & 10 \\
\hline 1975 & 740 & 95 & 5 & 1999 & 1395 & 196 & 9 \\
\hline 1976 & 923 & 94 & 7 & 2000 & 1814 & 282 & 25 \\
\hline 1977 & 1319 & 151 & 13 & 2001 & 1906 & 267 & 15 \\
\hline 1978 & 1526 & 177 & 19 & 2002 & 1333 & 247 & 16 \\
\hline 1979 & 2662 & 355 & 30 & 2003 & 1278 & 181 & 5 \\
\hline 1980 & 2662 & 446 & 40 & 2004 & 1166 & 167 & 10 \\
\hline 1981 & 2586 & 328 & 27 & 2005 & 2017 & 217 & 6 \\
\hline 1982 & 2544 & 307 & 16 & 2006 & 2758 & 342 & 3 \\
\hline 1983 & 2870 & 312 & 16 & 2007 & 3242 & 436 & 17 \\
\hline 1984 & 3495 & 494 & 16 & 2008 & 4805 & 682 & 32 \\
\hline 1985 & 2915 & 385 & 26 & 2009 & 4721 & 738 & 13 \\
\hline 1986 & 2860 & 427 & 38 & 2010 & 4826 & 682 & 22 \\
\hline 1987 & 3183 & 427 & 17 & 2011 & 5076 & 609 & 15 \\
\hline 1988 & 3721 & 554 & 39 & 2012 & 8522 & 901 & 19 \\
\hline 1989 & 4324 & 572 & 18 & 2013 & 12036 & 1405 & 31 \\
\hline 1990 & 3887 & 609 & 19 & 2014 & 16903 & 1545 & 43 \\
\hline 1991 & 4683 & 570 & 22 & 2015 & 14965 & 1620 & 30 \\
\hline 1992 & 5071 & 854 & 36 & 2016 & 13587 & 1146 & 28 \\
\hline $1993 *$ & - & - & - & 2017 & 10900 & 759 & 28 \\
\hline & & & & TOTAL & 181,691 & 21,924 & 941 \\
\hline
\end{tabular}

* Year 1993 is not complete in the database

Source: data (NCSTRT, 2017), elaboration: authors

The Figure 2 shows a comparison of the total number ("N") of terrorist attacks, attacks on soft targets and entertainment centers. 


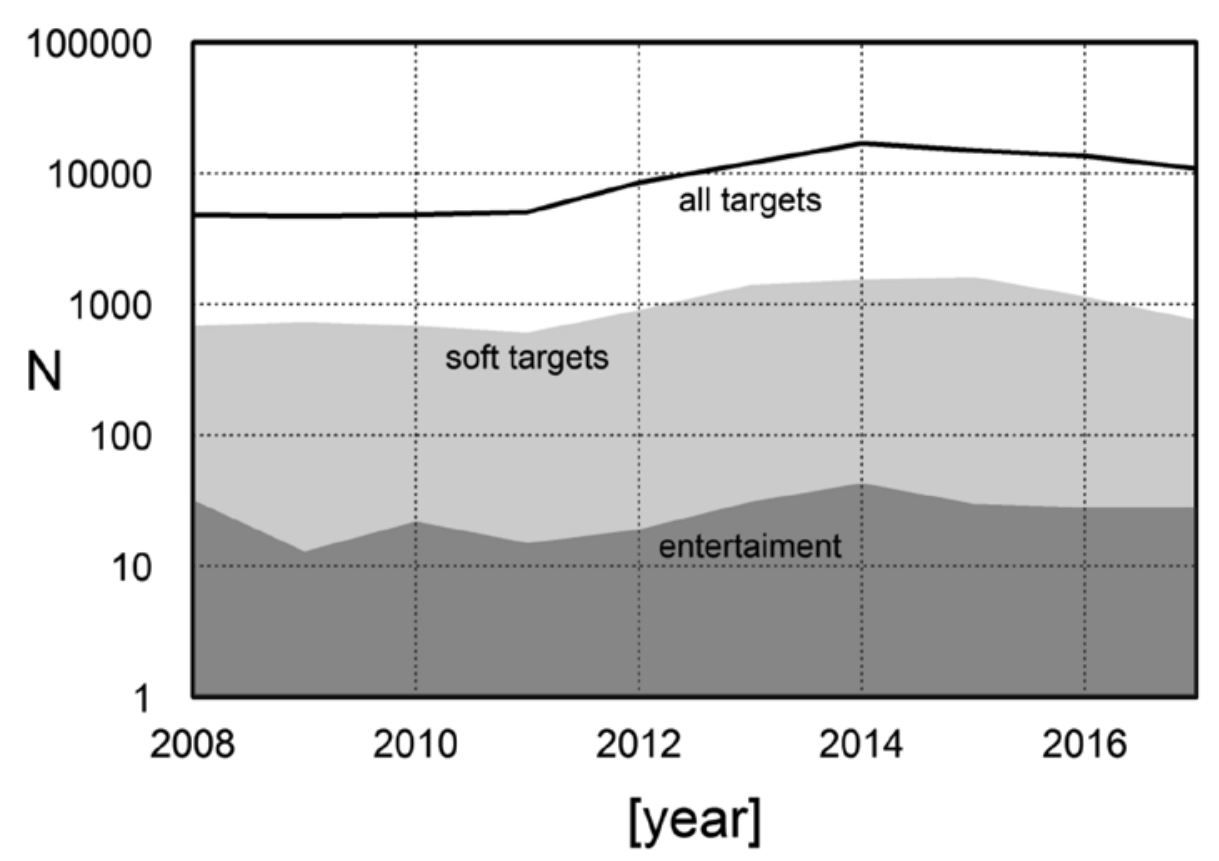

Fig. 2. Comparison of the number of all terrorist attacks, attacks on soft targets and attacks on entertainment industry in individual years

The greatest number of attacks on entertainment industry was recorded in 1995, namely 44 attacks and in 2014, namely 43 attacks. However, number of terrorist attacks on entertainment centers is a relatively small number compared to the total number of terrorist attacks.

Most of victims died as a result of terrorist attacks on entertainment centers in 1978, when 428 victims died. These were mainly bomb attacks. The second worst year with a large number of casualties was 2002 with a total of 214 dead. One of the biggest cases happened on October 23, 2002 on Dubrovka Theater in Moscow, Russia, when forty Chechen rebels took 912 hostages. The siege lasted until 26 October 2002, when Russian Special Forces filled the building with an unidentified gas intended to subdue the perpetrators. The gas killed all 40 perpetrators and 125 hostages. Five additional hostages were killed by the attackers during a shoot-out (National Consortium for the Study of Terrorism and Responses to Terrorism, 2017; Kalyugina et al., 2018).

Although the number of terrorist attacks after 2014 has been relatively decreasing, the risk of a terrorist attack is still high and it is important not to underestimate it. Unpreparedness for terrorist attacks was seen for example in a series of attacks on November 13 in Paris, where the security measures have completely failed. Most of victims died as a result of shooting assault in the Bataclan concert hall. An explosion was also heard at the Stade de France football stadium, where France with Germany played (Zeman et al., 2018).

Table 3 shows the number of victims in all terrorist attacks, attacks on soft targets and attacks on entertainment industry. 
Table 3. Comparison of the number of victims in terrorist attacks

\begin{tabular}{|c|c|c|c|c|c|c|c|}
\hline \multirow[b]{2}{*}{ Year } & \multicolumn{3}{|c|}{ Number of victims } & \multirow[b]{2}{*}{ Year } & \multicolumn{3}{|c|}{ Number of victims } \\
\hline & $\begin{array}{l}\text { terrorist } \\
\text { attacks }\end{array}$ & $\begin{array}{l}\text { attacks on } \\
\text { soft targets }\end{array}$ & $\begin{array}{c}\text { attacks on } \\
\text { entertainment } \\
\text { industry }\end{array}$ & & $\begin{array}{l}\text { terrorist } \\
\text { attacks }\end{array}$ & $\begin{array}{l}\text { attacks } \\
\text { on soft } \\
\text { targets }\end{array}$ & $\begin{array}{c}\text { attacks on entertainment } \\
\text { industry }\end{array}$ \\
\hline 1970 & 171 & 6 & 2 & 1994 & 7691 & 891 & 6 \\
\hline 1971 & 173 & 25 & 1 & 1995 & 6094 & 625 & 52 \\
\hline 1972 & 566 & 36 & 1 & 1996 & 6953 & 911 & 17 \\
\hline 1973 & 370 & 41 & 0 & 1997 & 10948 & 1102 & 40 \\
\hline 1974 & 542 & 107 & 2 & 1998 & 4678 & 650 & 4 \\
\hline 1975 & 617 & 122 & 0 & 1999 & 3388 & 417 & 0 \\
\hline 1976 & 672 & 99 & 0 & 2000 & 4422 & 467 & 8 \\
\hline 1977 & 456 & 11 & 0 & 2001 & 7738 & 838 & 55 \\
\hline 1978 & 1459 & 593 & 428 & 2002 & 4799 & 1186 & 214 \\
\hline 1979 & 2100 & 245 & 15 & 2003 & 3271 & 683 & 53 \\
\hline 1980 & 4428 & 502 & 82 & 2004 & 5713 & 1321 & 11 \\
\hline 1981 & 4851 & 289 & 21 & 2005 & 6311 & 855 & 4 \\
\hline 1982 & 5135 & 335 & 18 & 2006 & 9363 & 1635 & 4 \\
\hline 1983 & 9443 & 530 & 18 & 2007 & 12836 & 2080 & 11 \\
\hline 1984 & 10449 & 690 & 6 & 2008 & 9093 & 1989 & 18 \\
\hline 1985 & 7094 & 486 & 53 & 2009 & 9271 & 2294 & 20 \\
\hline 1986 & 5003 & 823 & 76 & 2010 & 7720 & 1415 & 9 \\
\hline 1987 & 6478 & 871 & 11 & 2011 & 8198 & 950 & 33 \\
\hline 1988 & 7192 & 1000 & 18 & 2012 & 15432 & 1597 & 17 \\
\hline 1989 & 8121 & 824 & 10 & 2013 & 22226 & 4050 & 115 \\
\hline 1990 & 7148 & 1090 & 51 & 2014 & 43550 & 4670 & 182 \\
\hline 1991 & 8429 & 938 & 16 & 2015 & 38422 & 4826 & 170 \\
\hline 1992 & 9745 & 1142 & 27 & 2016 & 34676 & 3095 & 158 \\
\hline $1993 *$ & - & - & - & 2017 & 26445 & 3190 & 183 \\
\hline & & & & TOTAL & 412,549 & 52,542 & 2,240 \\
\hline
\end{tabular}

* Year 1993 is not complete in the database

Source: data (NCSTRT, 2017), elaboration: authors

The comparison of the number of victims in all terrorist attacks, attacks on soft targets and entertainment centers is shown in Figure 3. 


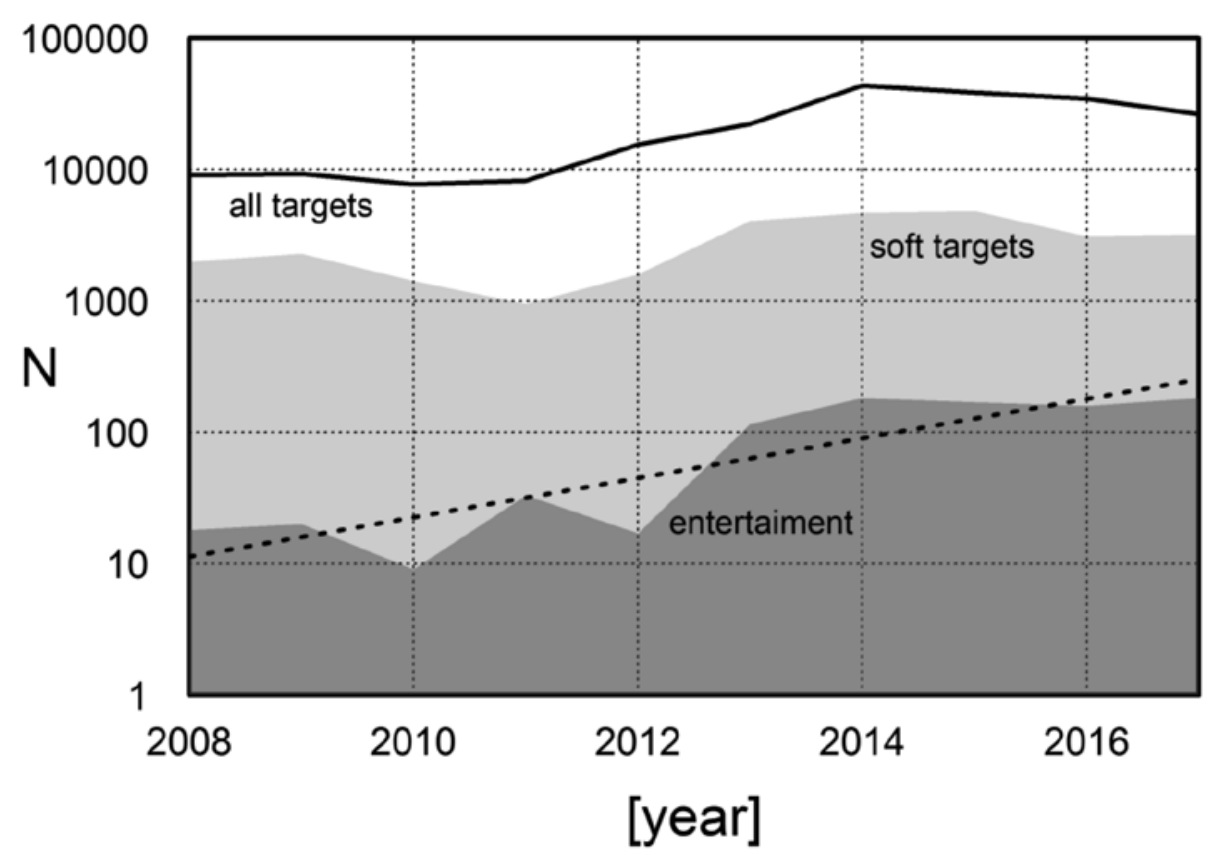

Fig. 3. Comparison of the number of victims in all terrorist attacks, attacks on soft targets and entertainment centers

As can be seen from Table 2, the number of terrorist attacks has often changed. Therefore it is very difficult to predict future development. This is obvious from the value of index $\mathrm{R}$ in individual predictions. We can observe a large increase in terrorist attacks and attacks on soft targets since 2012, when the number of attacks increased significantly in comparison with previous years. For example, while 2,017 violent attacks were committed in 2005 , these attacks increased sevenfold in 2015, as well as attacks on soft targets. In 2017, we can see a more significant decrease in the number of attacks - both total number of attacks, and attacks on soft targets. The reason for this decrease could be better preparedness of the bodies of the Integrated Rescue System, cooperation with the private sector, increase in public awareness, improved securing of soft targets and many more.

Because of terrorists' focus on soft targets, the number of victims unfortunately remains high. One of the reasons is the selection of the locations which are difficult to secure, such as Christmas markets, street demonstrations, queues in front of the museum etc. Another reason is, unlike in the previous attacks, which were planned over a long period of time and well thought-out, the quick execution of the terrorist's attack using a simple weapon therefore even the uncovering of a planned attack is almost impossible. This fact is supported by the graph (Fig. 5), where you can see a drastic decrease in the use of explosives when committing a terrorist attack on soft targets.

The use of explosives on entertainment centres is shown in Figure 6. It is evident that the use of explosives is often changing in time. However, there has been a decrease in the number of bomb attacks on entertainment centres. The attack is very often connected either to a vehicle driving into a crowd of people in front of an entertainment centre, the use of an explosive in a car and subsequent shooting, shooting in the entertainment facility, the use of a stab weapon etc (Otrrísal, 2018). Figure 4 ilustrates types of attack. 


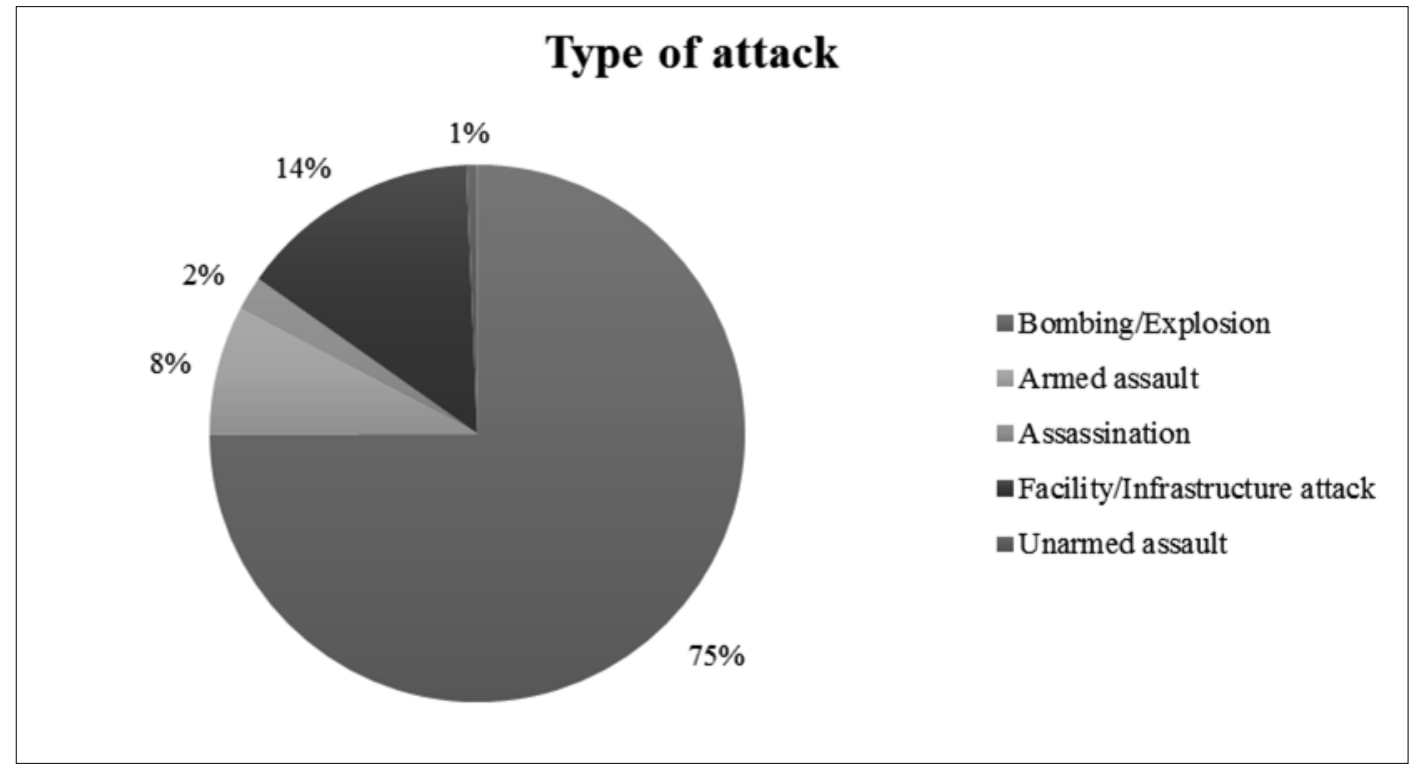

Fig. 4. Type of attack on entertainment centres

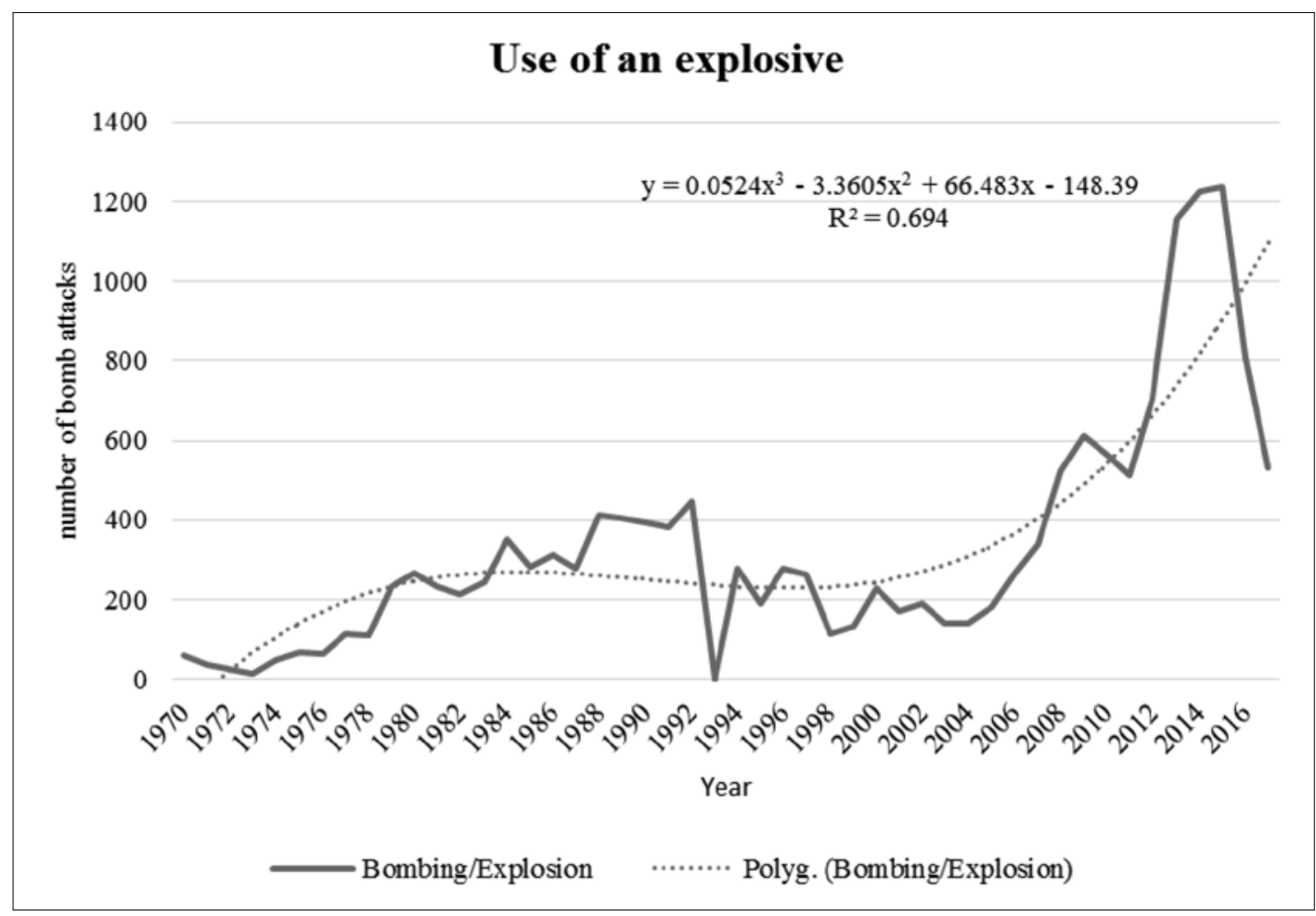

Fig. 5. Use of an explosive in individual years 


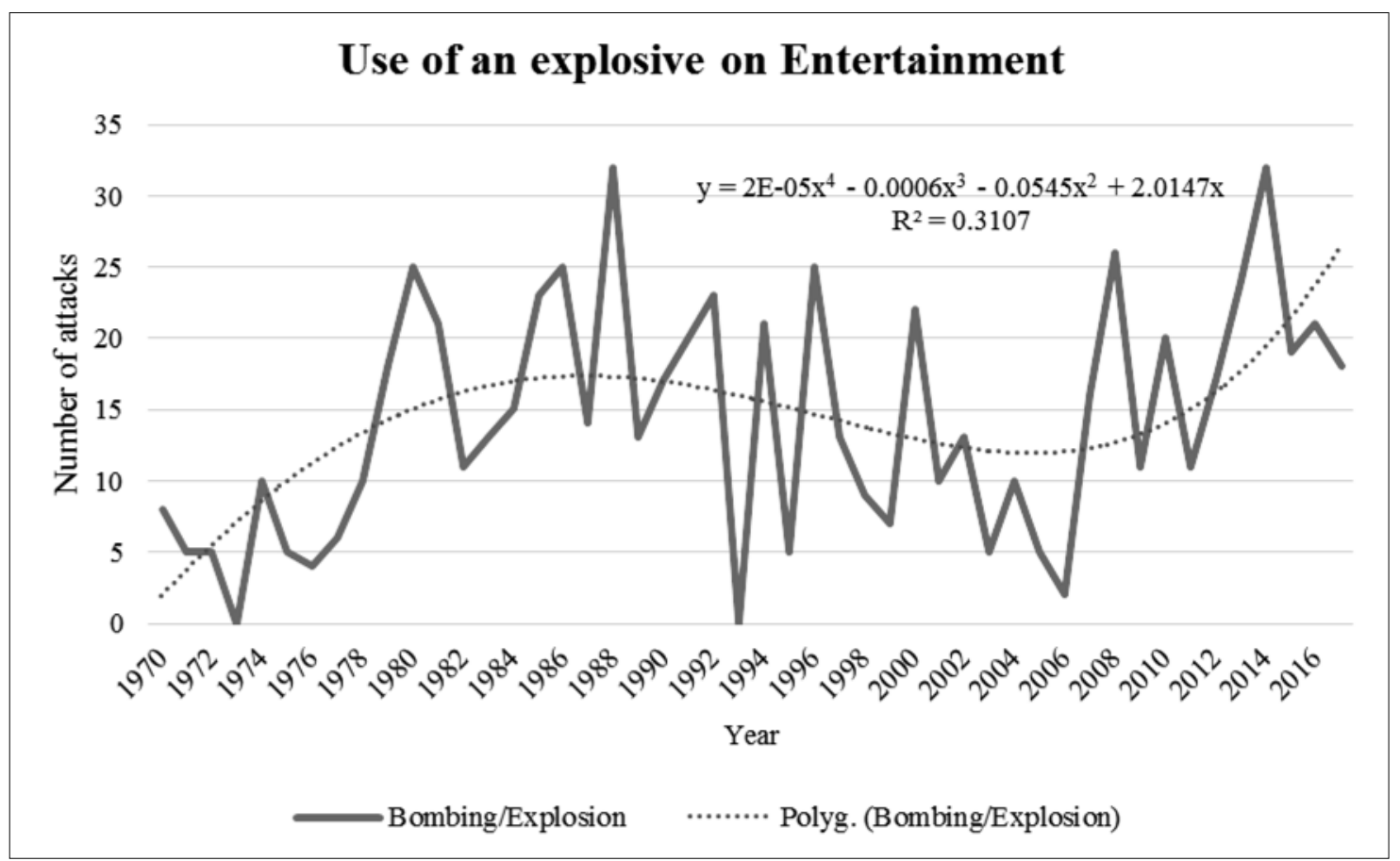

Fig. 6. Use of an explosive on entertainment centres in individual years

\subsection{Terrorist attacks $2011-2017$}

In this chapter, we want to show how rapidly the attacks on soft targets and entertainment centers increased. The following two graphs (Fig. 6 and Fig.7) show the number of victims of these attacks, a linear and logarithmic trend line given by the available data, and a forecast of upcoming time periods. For graphical reasons, the outlook is only one year ahead, however, the equations of these trends make it possible to calculate the outlook even for a much longer period. The reliability of these trends is determined by the reliability coefficient $\mathrm{R}^{2}$ and it is a sufficiently high.

However, it would be very interesting to verify the calculated and factual values. As was mentioned before, the data for 2016 and 2017 were not available at the moment of the first statistical evaluation. (NCSTRT, 2017). During our research, the data were completed and now 2016 and 2017 data are available in the database. So, when we look at the prediction for 2016 and 2017 (done in 2015) and the values available in the database, it can be observed that the number of realized attacks and a number of victims is less than it was predicted. Even though the number of terrorist attacks on entertainment centres decreased, the number of victims in entertainment centres increased in 2017. Table 4 gives the comparison of predicted and real data. For prediction were used the logarithmic trends.

Table 4. The number of victims in 2016 and 2017

\begin{tabular}{|c|c|c|c|c|}
\hline \multirow{2}{*}{ Year } & \multicolumn{2}{|c|}{ Precited number of victims } & \multicolumn{2}{c|}{ Real number of victims } \\
\cline { 2 - 5 } & attacks on soft targets & $\begin{array}{c}\text { attacks on } \\
\text { entertainment industry }\end{array}$ & attacks on soft targets & $\begin{array}{c}\text { attacks on } \\
\text { entertainment industry }\end{array}$ \\
\hline 2016 & 5485 & 192 & 3095 & 158 \\
\hline 2017 & 5904 & 209 & 3190 & 183 \\
\hline
\end{tabular}

Source: data (authors and NCSTRT, 2017), elaboration: authors 


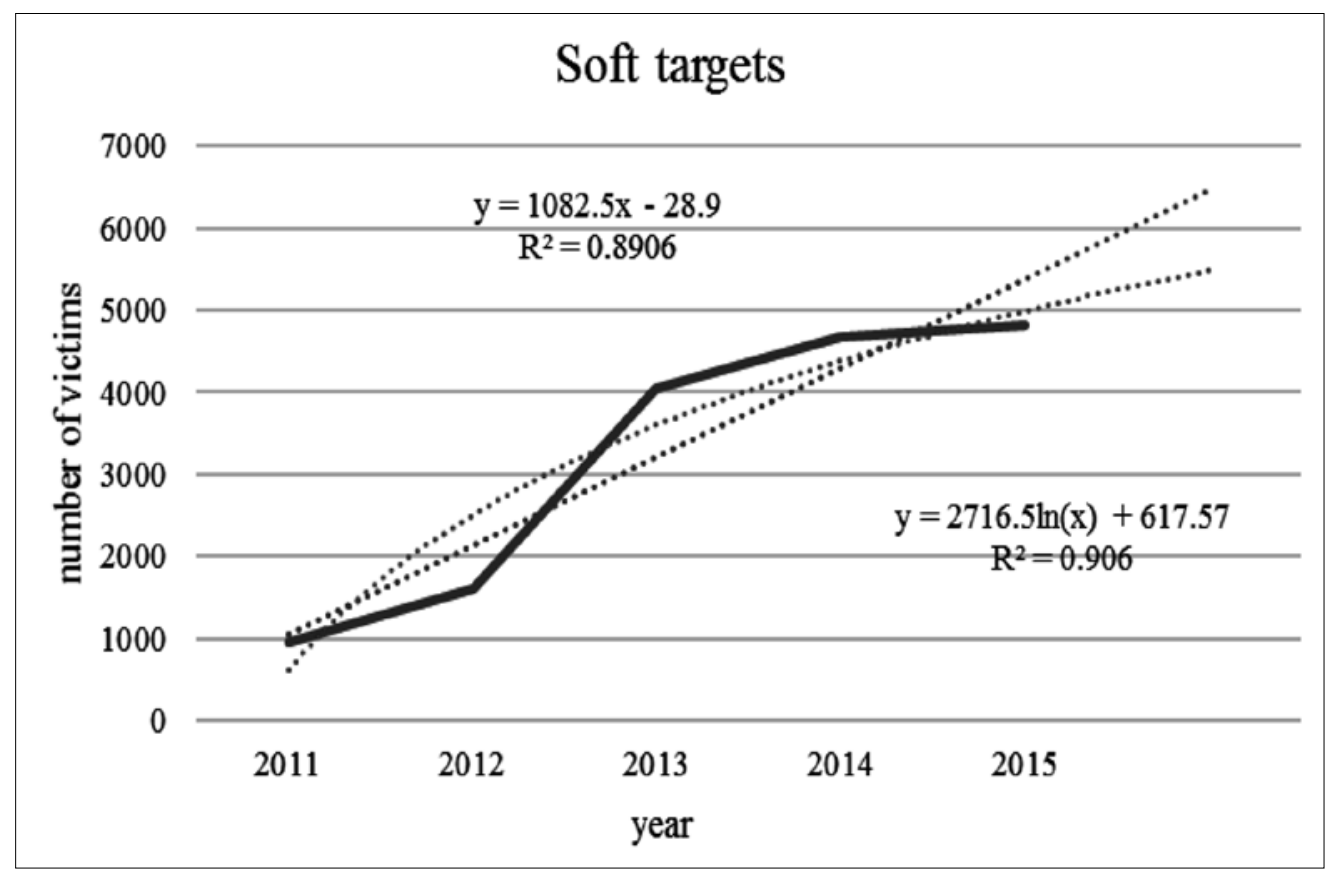

Fig. 7. Number of victims of terrorist attacks on soft targets in $2011-2015$

Especially from the linear trend equation $\mathrm{y}=1082.5 \mathrm{x}-28.9$ it is clear how the rapid increase in the victim count occurs in the past years. The direction of the trend line (blue) is steep, amounting to 1082.5. However, the logarithmic estimate of the trend (orange) for help seems more likely.

The increase in the number of victims in entertainment centers is fortunately not that high because the linear trend equation is $\mathrm{y}=45.5 \mathrm{x}-35.3$, the trend directive is "only" 45.5 . One of the possible reasons why this number is not that high could be the existence of at least basic safety measures, unlike areas accessible to the public (e.g. Christmas markets, demonstrations, parades etc.) where it is not possible to implement radical safety procedures (Vališ et al., 2010).

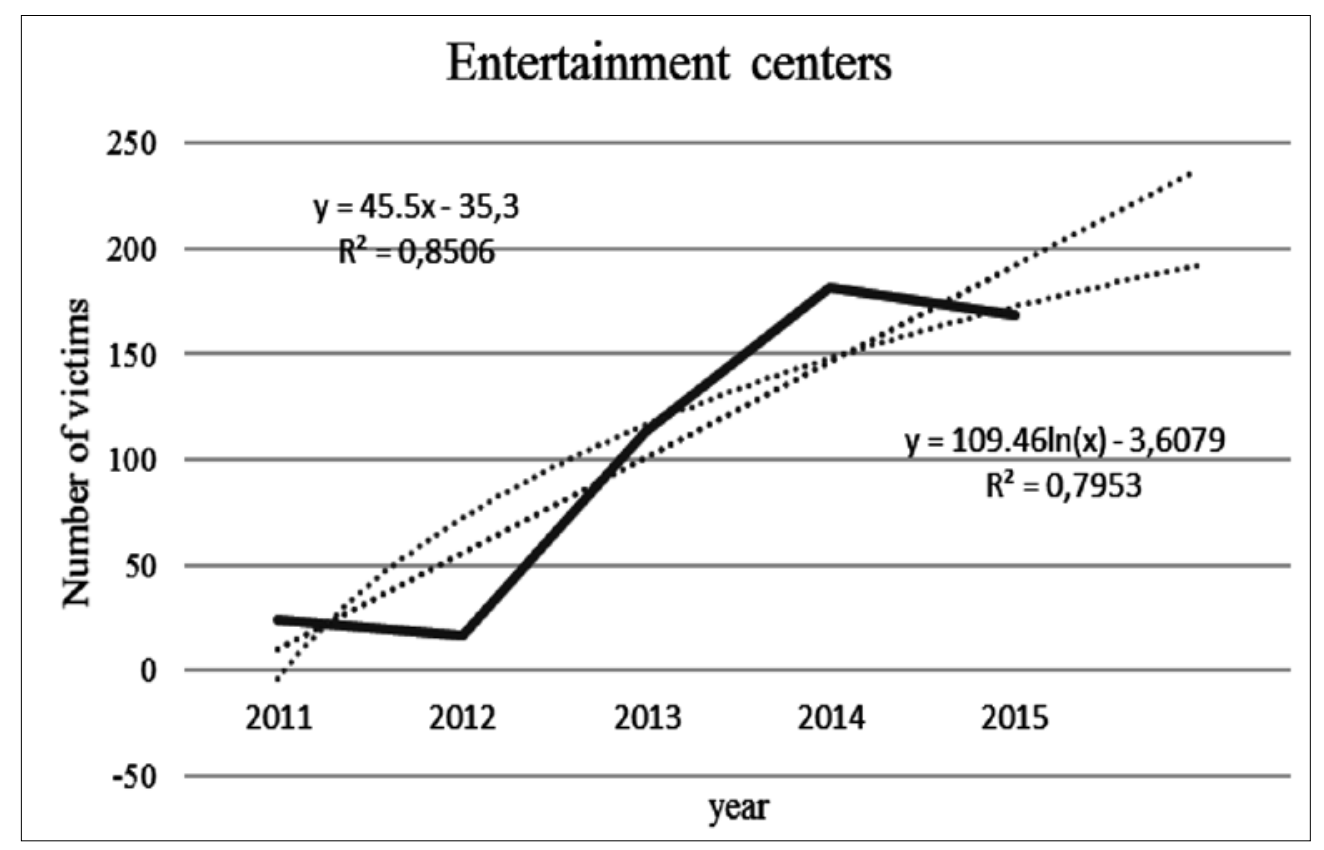

Fig. 8. Number of victims of terrorist attacks on entertainment centers in $2011-2015$ 


\section{Safety in the entertainment industry}

The security of soft targets is one of the most difficult security challenges. One of the countries most concerned with protecting soft targets is the United Kingdom. In relation to reducing the vulnerability of soft targets, the UK has developed a strategic framework of essential documents in the form of the so-called British Initiative. The following (three) documents include instructions aimed at reducing the vulnerability of soft targets:

- Working together to protect crowded places;

- Crowded places: the planning system and counterterrorism;

- Protecting crowded places: design and technical issues.

These documents are closely linked to The National Counter Terrorism Security Office in cooperation with the Centre for the Protection of the National Infrastructure and the Royal Institute of British Architecture in counter-terrorism planning.

The aforementioned documents are complemented by the following studies:

- Crowded Places: A response to the consultation;

- Crowded Places: Equality Impact Assessment of Guidance and Response to Recommendations;

- Crowded Places: Impact Assessment.

All of the above documents complement the material of safety recommendations for specific groups of selected objects in the form of handbooks. These guides are created for every soft target and aimed at their security, helping all owners to secure their object. Finally, attention is paid to a number of questions (checklists) to assist them in identifying the hazards and risks associated with counter terrorism planning (GOV.UK, 2014, Tvaronaviciene et al., 2018).

In other European countries, the concept of the securing of soft targets is still a bit suppressed. The frequency of terrorist attacks is increasing in Europe. Examples of the worst terrorist attacks in Europe in the last year are:

Table 5. Example of terrorist attacks

\begin{tabular}{|c|c|}
\hline Louvre knife attack: February 3,2017 & Manchester attack: May 22, 2017 \\
\hline Westminster attack: March 22, 2017 & London Bridge attack: June 3, 2017 \\
\hline Stockholm attack: April 7, 2017 & Finsbury Park attack: June 19, 2017 \\
\hline Paris shooting: April 20, 2017 & Spanish attacks: August 17, 2017 \\
\hline
\end{tabular}

Source: data (Foster, 2017), elaboration: authors

The security of soft targets is a global problem. Most countries are trying to increase the safety of these targets. For example, in the Czech Republic, there was founded a working group to methodically support managers and owners of soft targets. There was issued a methodology "Basics of protection of soft targets" which focuses primarily on preventing and mitigating terrorist attacks (Kalvach, 2016). A brochure has also been published about 10 principles for Making the Soft Target More Resilient, Evaluating the Threat to a Soft Target, Safety Plan of a Soft Target, and Safety Standards for Organizers of Sport, Cultural, and Social Events. In the Czech Republic, 359 million CZK will be set for the protection of soft targets in the years $2019-2021$. The aim is to motivate owners and managers of soft targets to improve their ability to prepare themselves and respond to a possible violent attack. The government of the Czech Republic, at its session on July 24, 2017, approved the release of the fund support which will be received mainly by state, municipal, or private noncommercial soft targets and much more.

The protection of soft targets has also been reflected in several security documents, which are:

- Strategy of the Czech Republic for Combating Terrorism from 2013;

- National Security Audit;

- Anti-terrorist package (defines protection of soft targets as one of the main priorities). 
To find out the safety of soft targets, it is possible to use the method of safety audit and checklist analysis. The safety audit is a structured process whereby information is collected relating to the efficiency, effectiveness, and reliability of the total health and safety management system of a company. It is a formal review in which an independent and qualified auditor prepares a report on the assessed security risks of the project and submits proposals for their elimination (Beňová et al., 2017; Project Management Knowledge, 2017). Using the method of safety audit, the weaknesses in the security of places of entertainment centers can be identified. The checklist analysis is one of the simplest and quickest ways to identify risks (Oulehlová et al., 2015). One of its advantages is that it is suitable for team members who have less experience. The checklist is usually developed based on the knowledge obtained from previous projects that are similar to the current one, as well as historical information and from other sources of information (Beňová et al., 2017; Safeopedia, 2017). An example of the questions is shown in Table 5.

Table 6. An example of the questions (checklist)

\begin{tabular}{|c|c|c|c|}
\hline & Yes & No & Unsure \\
\hline \multicolumn{4}{|l|}{ Do I have enough security staff to protect the building/area? } \\
\hline \multicolumn{4}{|l|}{ Is the security staff deployed throughout the building? } \\
\hline \multicolumn{4}{|l|}{ Is the security staff adequately well-trained? } \\
\hline \multicolumn{4}{|l|}{ Is the camera system turned on? } \\
\hline \multicolumn{4}{|l|}{ Do I have a camera system regularly maintained? } \\
\hline \multicolumn{4}{|l|}{ Is the camera system in the whole building / areas? } \\
\hline \multicolumn{4}{|l|}{ Do I constantly monitor cameras images or playback overnight recordings for evidence of suspicious activity? } \\
\hline \multicolumn{4}{|l|}{ Do I have physical barriers to prevent unauthorized persons from entering? (fencing etc.) } \\
\hline \multicolumn{4}{|l|}{ Do I prevent vehicles from parking close to the building/arena or under the structure? } \\
\hline \multicolumn{4}{|l|}{$\begin{array}{l}\text { Do I have in place physical barriers to keep all but authorized vehicles at a safe distance and to mitigate against a } \\
\text { hostile vehicle attack? }\end{array}$} \\
\hline \multicolumn{4}{|l|}{ Do I conduct random overt searches of vehicles as a visual deterrent? } \\
\hline \multicolumn{4}{|l|}{ Have I reviewed the use and location of all waste receptacles in and around building/arena? } \\
\hline \multicolumn{4}{|l|}{ Do I keep furniture to a minimum to provide little opportunity to hide devices? } \\
\hline \multicolumn{4}{|l|}{ Are reception staff and deputies trained and competent in managing telephoned bomb threats? } \\
\hline \multicolumn{4}{|l|}{ Are reception staff and deputies trained to handle an emergency? } \\
\hline \multicolumn{4}{|l|}{ Do I regularly meet with staff and discuss security issues? } \\
\hline \multicolumn{4}{|l|}{ Do I have access control measures for persons and vehicles? } \\
\hline \multicolumn{4}{|l|}{ Are visitors sufficiently controlled before entering the building/area? } \\
\hline \multicolumn{4}{|l|}{ Are all luggage adequately inspected? } \\
\hline \multicolumn{4}{|l|}{$\begin{array}{l}\text { Are all employees issued with photographic and barcode identification retained on an up to date database and } \\
\text { checked before access is permitted? }\end{array}$} \\
\hline $\begin{array}{l}\text { Do I have an access control policy for press and photographers, allowing entry only for those whose identity is } \\
\text { confirmed and have booked in advance? }\end{array}$ & & & \\
\hline
\end{tabular}

Source: authors

Each checklist should be done for a given object or at least a category of objects individually, in order to be as effective as possible.

\section{Received results - Security options}

The first step towards determining if my object can be regarded as a soft target is the evaluation of the following criteria which were selected from the literature research and past attacks:

Cr. 1 population density

Cr. 2 time;

Cr. 3 object location;

Cr. 4 openness of the area (object);

Cr. 5 symbolicalness; 
Cr. 6 ussed safety measures;

Cr. 7 media presence;

Cr. 8 popularity/visibility of the area to the public;

Cr. 9 occurrence of dangerous (CBRN) substances in the area.

Table 7 presents the results of the questionnaire survey. The individual rows indicate the number of responses that ranked the criterion in the given order. For example, criterion Cr.3 "location of object" ranked 4 experts to second place of importance, 33 experts to 3 place, 18 to fourth place in the evaluation of the importance of the criterion, etc.

Table 7. Survey results

\begin{tabular}{|c|c|c|c|c|c|c|c|c|c|}
\hline Criterion order & Cr. 1 & Cr. 2 & Cr. 3 & Cr. 4 & Cr. 5 & Cr. 6 & Cr. 7 & Cr. 8 & Cr. 9 \\
\hline 1 & 57 & 0 & 0 & 20 & 2 & 9 & 0 & 0 & 0 \\
\hline 2 & 31 & 0 & 4 & 39 & 6 & 8 & 0 & 0 & 0 \\
\hline 3 & 0 & 3 & 33 & 27 & 20 & 0 & 1 & 4 & 0 \\
\hline 4 & 0 & 7 & 18 & 2 & 45 & 2 & 11 & 3 & 0 \\
\hline 5 & 0 & 31 & 21 & 0 & 6 & 3 & 7 & 10 & 10 \\
\hline 6 & 0 & 16 & 1 & 0 & 8 & 23 & 20 & 5 & 15 \\
\hline 7 & 0 & 16 & 11 & 0 & 1 & 15 & 14 & 11 & 20 \\
\hline 8 & 0 & 6 & 0 & 0 & 0 & 22 & 24 & 28 & 8 \\
\hline 9 & 0 & 9 & 0 & 0 & 0 & 6 & 11 & 27 & 35 \\
\hline
\end{tabular}

Source: authors

For clarity, the results presented at Table 7. are illustrated also graphically at Figure 8, where the number of particular orders assigned by experts to the criterion is presented in the column of particular colour.

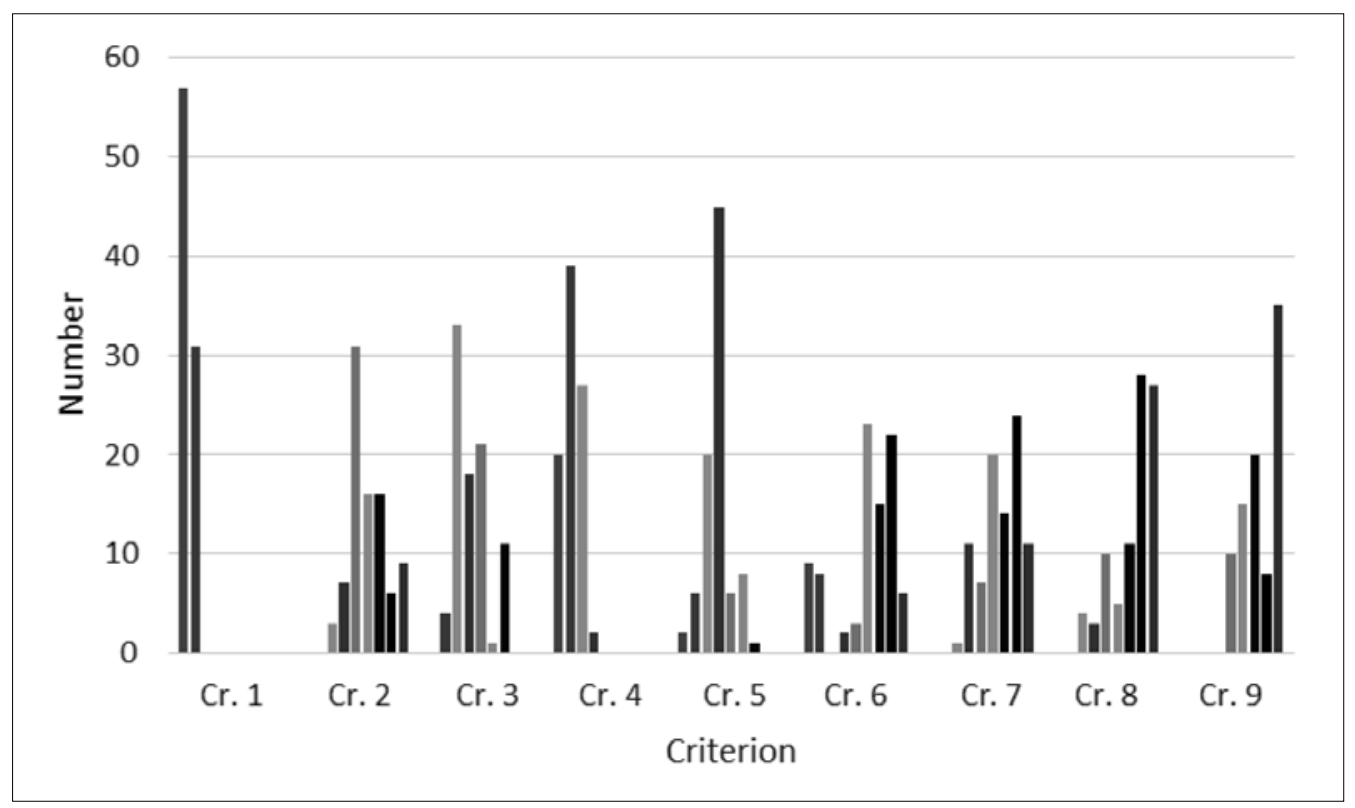

Fig. 8. Number number of particular orders assigned by experts to each criterion

Source: authors

Every object is specific and it is important to view it independently of other soft targets. The next step is to consider whether my object can be a potential target of terrorist or other violent attack. One of the possibilities is to determine the probability and effect of an attack. In terms of the attack probability, it is important to consider the availability of devices used to commit the attack, the occurrence of this type of attack and the complexity of it. 
Regarding the effect of an attack, it is important to focus especially on the impact on the lives and health of citizens. The total level of the object threat is calculated by multiplying the probability of occurrence and its impact.

The degree of importance of the given criterion is expressed using the weight of the criterion. One of the basic methods of assigning weight is to sort the criterion by importance. The scales have to be normalized so that their sum is 1 . The weights of the criteria can be calculated, for example, by sorting or evaluating the criteria. One of the simplest methods is a sorting and summing method. According to it, we define the normalized weights $w_{j}$ of the $\mathrm{j}$-th criterion as follows:

$$
W_{j}=\frac{n-r_{j}+1}{\sum_{j} n-r_{j}+1}
$$

where $n$ is the number of criteria $(\mathrm{k}=1,2, \ldots, \mathrm{n})$ and $r_{j}$ is the position of order of the criterion.

Table 8. Results

\begin{tabular}{|l|c|c|c|}
\hline & $\begin{array}{c}\text { Sum of the order numbers } \\
\text { assigned to each criterion }\end{array}$ & $\begin{array}{c}\text { Assign Criterion } \\
\text { Order }\end{array}$ & $\begin{array}{c}\text { Significance assign } \\
\text { to each criterion }\end{array}$ \\
\hline Population density & 119 & 1 & 0,211 \\
\hline Time & 529 & 4 & 0,142 \\
\hline Object location & 367 & 2 & 0,150 \\
\hline Openness of the area (object) & 187 & 3 & 0,180 \\
\hline Symbolicalness & 339 & 7 & 0,151 \\
\hline Used safety measures & 521 & 6 & 0,062 \\
\hline Media presence & 591 & 8 & 0,070 \\
\hline Popularity/visibility of the area to the public & 648 & 9 & 0,031 \\
\hline Occurrence of dangerous (CBRN) substances in the area. & 659 & & 0,01 \\
\hline Sum & & & 0,99 \\
\hline
\end{tabular}

Source: authors

Soft targets can be secured by using security components. According to guidelines Basic of soft targets protection (Kalvach, 2016) the security components were divided into three basic categories - personnel safety, electronic devices and mechanical devices.

Personnel safety is a system of measures to prevent or ensure the difficulty of access by unauthorized persons. In the entertainment industry, for example theaters, cinemas, stadiums, clubs, etc., there is always at least one guard member who lets people in and check their tickets, or in the case of bigger events the guard member checks personal belongings. The question remains whether he could avert a terrorist attack. As a rule, they are not trained and experienced workers who can respond to an emergency situation. Well-trained security staff is a very effective security tool to deter potential attackers and immediately respond to mitigate their impact, especially in case of an emergency with mass health disabilities (Kalvach, 2016; Švarcová, et. al., 2016).

Electronic devices are a system of measures to capture the suspect in a timely manner, possibly identifying and capturing an attacker after an attack has been committed.

The most common electronic devices are camera systems, which can identify a suspect behavior before entering the object, or can help identify the perpetrators of an attack. At bigger events such as football matches or festivals, guards can be seen using portable X-ray devices to detect weapons and explosives.

Mechanical devices are systems of measures serving mainly to prevent the entry of potential attackers, or their authorization while entering the facility. The most frequently used mechanical devices are fences serving to prevent the entry of unauthorized persons, and turnstiles for identification of people entering the building (Kalvach, 2016). 


\section{Discussion and findings}

In terms of security of selected soft targets, however, it is essential to combine the security features appropriately. Introducing the above security features greatly contributes to increasing the resilience of soft targets against violent attacks. If we evaluate cultural centers (cinemas, clubs, theaters), most of them will only have a security officer who will let us in and check the tickets. However, no one checks whether we are smuggling something inside. On the other hand, sports events (hockey, football matches), festivals, and concerts are better guarded. However, even in these cases, we often encounter the possibility of passing a suspect object into the premises. Therefore, it is important to set certain security measures to avoid such mistakes and possibilities.

By evaluating the availability of security measures, it shows that the security of entertainment venues is at a very low level. There is no manual in the Czech Republic to deal with the introduction of security features for soft targets, as is the case for example in the United Kingdom. It is necessary to increase the number of security personnel, frequency of police checks, training of security staff to deal with emergencies and the awareness of other employees and people about the possibility of the occurrence of a terrorist attack. Training of public is a very important step to ensure conditions for adequate response in case of disasters and other emergencies. Conditions for successful solutions can be created by acquiring knowledge and skills, having mastered technical and technological readiness to manage critical crisis situations and so on. It is also necessary to minimize the impact of terrorist attack. Camera systems are very important in monitoring not only buildings, but also places where the events take place. The camera systems help detect suspicious behavior in time. These and many other security measures can significantly reduce the likelihood of a terrorist attack and its possible impacts (Hošková-Mayerová, 2016).

The safety of soft targets in the entertainment center area (and in general) is at a low level. The security of a soft target is always in the hands of its owner and operator. In the Czech Republic, there is an increase in the awareness of owners and operators of soft targets about possible violent attacks and the possibilities of securing their objects. In order to protect soft targets and increase their security, the Basics of Protection of Soft Targets Methodology was published, which focuses on protection against serious violent attacks. In addition, a hotline has been set up for operators and owners of soft targets where they can consult experts on security of their premises or organized events. Moreover, a working group was set up to provide methodological support to operators and owners of soft targets. The institution Soft Target Institution Protection also deals with the development of soft targets security. Finally, the safety standard "ČSN 734400 Prevention of Crime - Safety Management in the Planning, Implementation and Use of Schools and School Facilities" was issued, which was created mainly on the basis of the fatal event that took place at an elementary school. However, it is also necessary to focus on the physical security of the object and increase its resistance to violent attacks. One possibility is to create a checklist of issues, so-called Check List, and to evaluate the safety of the object and propose new measures.

\section{Conclusions}

The threat of terrorist attacks is a very serious issue. From the analysis of data available in the Global terrorism database, it is evident that the number of terrorist attacks has increased significantly especially in the last 10 years. As can be seen from the analysis of the current situation and recent events, terrorist attacks are increasingly focused on soft targets. Due to the wide range of potential soft targets, it is impossible to determine where and when other attacks will be committed. A very likely target is the area of entertainment, where security measures are unfortunately often underestimated. To ensure the safety of visitors (persons), it is very important to have a comprehensive approach in which security personnel and organizers of entertainment events will be welltrained. Professional security staff is a very effective security and safety tool to identifying potential attackers, respond quickly and mitigate their impact. It is advisable to inform people about terrorist threats, methods to detect suspicious behavior of the attackers and their characteristics, and knowledge of safety procedures and escape routes when an attack occurs. 
Another important security component is the complex camera system and other modern devices (X-ray scanners, detectors of explosives, entry and attendance control systems etc.) that will monitor participants attending entertainment venues.

Reviews of available literature and an analysis of the current state also showed that the United Kingdom is at the forefront of security in Europe. The United Kingdom is very concerned about the security of soft targets and unlike other countries, has made guides to secure these objects that can help all owners. These guides can greatly help to prevent a potential terrorist attack, and should be used by all owners to increase the safety of soft targets and visitors.

In the Czech Republic, security components are currently being tested at the airport and selected metro stations in Prague. From the standpoint of security forces and organizers of entertainment events, attention should be paid to developing awareness of threats, preventing and eliminating any indication of attacks on soft targets. It is apparent that people do not deal with this issue until they themselves have become the victim of terrorist attacks.

Given that neither the Czech legislation nor the European Union legislation has in any way undefined the definition of the soft target concept and it is therefore not clear which objects fall within it, the authors of the article focused on solving this problem. Based on controlled interviews with practitioners, the authors identified the most important criteria for categorizing the object into the "soft target" category. In addition, a questionnaire survey was carried out, where the basic research question was the degree of significance of each criterion. From the results, the rate of the individual criteria was then determined by the order method. Thanks to this knowledge, this result can now be used to determine the degree of risk to the individual object. Once the risk of a given object is known, measures can be taken to remedy the deficiencies in the safety of the object, respectively. Other security measures. For this reason, the authors of the article have also prepared a sample of a check list. Using the method of safety audit, the weaknesses in the security of places of entertainment centers can be identified.

Finally, we have to say that is necessary to focus more on securing soft targets and to prepare a suggested handbook for specific soft targets that can help operators and owners to ensure the safety of visitors and employees.

\section{References}

Beňová, P.; Vašková, M.; Navrátil, J. 2017. Ensuring the security of selected soft targets. In Safety and Reliability: Risk management Proceedings of the European Safety and Reliability Conference, ESREL. Slovenia, CRC Press/Balkema, 2017. ISBN 978-1-138-62937-0.

Checklist Analysis. Project Management Knowledge [online]. [cit. 2017-09-03]. Available on the Internet: https://project-managementknowledge.com/definitions/c/checklist-analysis/

European Commission. 2017. "Fourth Progress Report towards an Effective and Genuine Security Union.” Brussels.

Foster, A. Terror attacks timeline: From Paris and Brussels terror to most recent attacks in Europe. Express [online]. [cit. 2017-1025]. Available from: http://www.express.co.uk/news/world/693421/Terror-attacks-timeline-France-Brussels-Europe-ISIS-killingsGermany-dates-terrorism

Hošková-Mayerová, Š. 2016. Education and Training in Crisis Management. Book Series: European Proceedings of Social and Behavioural Sciences, Future Academy, Vol. 16, 849-856. ISSN 2357-1330. https://doi.org/10.15405/epsbs.2016.11.87

Kalvach, Z. 2016. Basics of soft targets protection: Guidelines. Prague.

Kalyugina, S.; Pianov, A.; Tvaronaviciene, M. et al. 2018. Depopulation and external migration as the institutional risks to personnel safety. Journal of institutional studies, Vol. 10, 125-144. https://doi.org/10.17835/2076-6297.2018.10.4.125-144

NCSTRT- National Consortium for the Study of Terrorism and Responses to Terrorism (START). 2017. Global Terrorism Database [Data file]. Available on the Internet: http://www.start.umd.edu/gtd

Otřísal, P. et al. 2018. Testing Methods of Assessment for the Chemical Resistance of Insulating Materials Against the Effect of Selected 
Acids. Materiale plastic. Vol. 55 (4), 545-551.

Otřísal, P. et al. Preparation of Filtration Sorptive Materials from Nanofibers, Bicofibers, and Textile Adsorbents without Binders Employment, Nanomaterials. Vol. 8 (8). DOI: https://doi.org/3390/nano8080564

Oulehlová, A. et al., 2015. Preparedness of critical infrastructure subjects in energy sector for crisis situations. Safety and Reliability of Complex Engineered Systems - Proceedings of the 25th European Safety and Reliability Conference. 229-236. ISBN 978-1-138-02879-1.

Protection of soft targets [online]. In: Ministry of the Interior. [cit. 2016-10-24]. Available on the Internet: http://www.mvcr.cz/clanek/ ochrana-mekkych-cilu.aspx

Protecting crowded places from terrorism. GOV.UK [online]. 2014 [cit. 2017-08-31]. Available on the Internet: <https://www.gov.uk/ government/collections/crowded-places

Safety Audit. Safeopedia [online]. [cit. 2017-09-03]. Available on the Internet: $<$ https://www.safeopedia.com/definition/486/safetyaudit>.

Soft targets protection. Ministry of the Interior [online]. Prague, 2017 [cit. 2017-05-22]. Available on the Internet: http://www.mvcr.cz/ clanek/ochrana-mekkych-cilu.aspx

Švarcová, I.; Hošková-Mayerová, Š; Navrátil, J. 2016. Crisis Management and Education in Health, Book Series: European Proceedings of Social and Behavioural Sciences, Vol. 16, 255-261. https://doi.org/10.15405/epsbs.2016.11.26

Terminology dictionary of the Ministry of the Interior, Czech Republic, Prague 2016, p. 129. Available on the Internet: <http://www. mvcr.cz/clanek/terminologicky-slovnik-krizove-rizeni-a-planovani-obrany-statu.aspx

Tvaronaviciene, M.; Masood, K.; Javaria, K. 2018. Preconditions of the eurozone economic security: How to overcome liquidity risk and cost inefficiency in leading banks of UK and Germany. Polish journal of management studies. Vol. 18, 418-427. DOI: https://doi. org/10.17512/pjms.2018.18.1.31

Vališ, D.; Žák, L.; Walek, A.; Pietrucha-Urbanik, K. 2014. Selected mathematical functions used for operation data information. Safety, Reliability and Risk Analysis: Beyond the Horizon. 1303-1308. ISBN: 978-1-138-00123- 7.

Vališ, D.; Vintr, Z.; Koucky, M. 2010. Contribution to highly reliable items' reliability assessment. Proc. of the European Safety and Reliability Conference ESREL, Prague, Czech Republic. Reliability, Risk and Safety: Theory and Applications. 1321-1326. ISBN: 9780-415-55509-8.

Zeman, T. Břeň, J. Urban, R. 2018. Profile of a lone wolf terrorist: a crisis management perspective. Journal of Security and Sustainability Issues, Vol. 8, 5-18. ISSN 2029-7017.

\section{Aknowledgements}

This research was supported by MŠMT ČR, research project no. SV17-FVL_K106-BEN: Identification and security of places with high population movement. 
Short biographical note about the contributors at the end of the article (name, surname, academic title and scientific degree, duties, research interests):

Petra BEŇOVÁ is the internal doctoral student at the Department of Emergency Management, Faculty of Military Leadership at the University of Defence in Brno. On the frame of the doctoral study she deals with measures to protect the population in the area of soft targets. She graduated the bachelor's degree program "Protecting the Population" in 2014 and master's program in the same field at the identical University in 2016.

ORCID ID: orcid.org/ 0000-0003-4723-5985

Šárka HOŠKOVÁ - MAYEROVÁ Accomplished researcher and educator. Currently appointed Associate Professor of mathematics at the University of Defence of the Czech Republic. Research focus on contemporary (fuzzy) hypergroup theory. Current concentration also on mathematical modelling and statistics, mainly its applications into social sciences and crisis management. Invited guest lecturer to universities in Italy, Romania, Lithuania, Greece, Mexico, Japan and Iran.

ORCID ID: orcid.org/0000-0002-3305-529X

\section{Josef NAVRÁTIL}

He graduated from the University of Chemical Technology in Pardubice, field of study - Production of Very Pure Substances. In 1991 he submitted his dissertation at the Military University of the Ground Forces in the field of screening aero-dispersions. In the last decade he has been specializing in the diagnostics of harmful substances in particular components of the environment and in the possible interactions of dangerous substances, leaked or occurred during disasters. He has a lot of experiences concerning experimental diagnostic work and methodology of research project solutions. Since 1998 he has been working as chief of the Department of Civil and Environmental Protection at the University of Defence, in 2014 renamed to the Department of Emergency management, Faculty of Military Leadership. He is an author of more than 110 scientific and professional publications, conference presentations, research and technical reports, expert's reports and reviews and some authorship certificates. 